\title{
PREDICTION OF COMPACTION CHARECTERISTICS OF SOIL USING PLASTIC LIMIT
}

\author{
K. Hannah Jyothirmayi ${ }^{1}$, T. Gnanananda ${ }^{2}$, K.Suresh ${ }^{3}$ \\ ${ }^{\text {I}}$ P.G Student, Department of Civil Engineering, VNR Vignana Jyothi Institute of Engineering and Technology, \\ Telengana, India \\ ${ }^{2}$ Asst. Professor, Department of Civil Engineering, VNR Vignana Jyothi Institute of Engineering and Technology, \\ Telengana, India \\ ${ }^{3}$ Asst. Professor, Department of Civil Engineering, VNR Vignana Jyothi Institute of Engineering and Technology, \\ Telengana, India
}

\begin{abstract}
In all kinds of earthwork constructions, the laboratory determination of the compaction characteristics of the soils plays an important role. Soil compaction is defined as the method of increasing the density of the soil by application of mechanical energy. The principal reason for the compaction of the soil is to produce a soil mass which can satisfy the three basic criteria. Firstly, the reduction of subsequent settlement of the soil mass, under working loads. Secondly, for the reduction in permeability which will subsequently avoid built up of large water pressures causing liquefaction problems and is also important for retaining water in case of earth dams. Thirdly, it is used for increasing the shear strength of the soils. But the determination of compaction characteristics in laboratory is laborious. It requires significant time and effort. Hence, there is a necessity for prediction of compaction characteristics with the help of correlating it with index properties of soil which can be determined easily. The plastic limit of soil can be found effortlessly and it bears a good correlation with compaction characteristic, namely optimum moisture content (OMC). In this paper, a study is conducted on nine types of fine grained soils like black cotton soil, red clay, china clay, marine clay, silty clay etc. collected from different parts of Telengana and Andhra Pradesh. And a simple equation has been suggested using regression analysis to obtain the optimum moisture content of a soil from the plastic limit, thereby eliminating the dependence of the proctor test for determination of $O M C$.
\end{abstract}

Keywords: Compaction, plastic limit, optimum moisture content, Fine grained soils, Proctor test

\section{INTRODUCTION}

Compaction of soil is a process of application of mechanical energy for its densification by removal of air voids and rearranging the particles. The reduction in the voids ratio makes it more difficult for the water to flow through the soil. This is important if the soil is being used for retaining water such as in case of an earth dam. It also helps in preventing the water pressures that causes soil to liquefy during earthquakes. So modification of soil is a vital process for improving its engineering properties and it is also essential in many applications such as highway, railway subgrades, air field pavements and in constructing earth and earth retaining structures. The soil mass is compacted to achieve the three basic criteria i.e. reduction in subsequent settlement of soil mass under working loads, reduction in permeability and increases the shear strength of the soil.

The compaction characteristics are mainly dependent on four factors, namely, water content, type of soil, amount of compaction and method of compaction.

Prior to the field compaction, the determination of compaction characteristics namely, optimum moisture content and maximum dry density is necessary. In laboratory these characteristics can be determined only by proctor test which is a laborious and time consuming method. Therefore, there is a need of correlating the compaction characteristics with consistency limits as they are easy to determine. Plastic limit bears a good correlation with OMC than any other consistency limits.

Liquid limit, plasticity index and shrinkage index do not bear any correlation with the compaction characteristics. It is quite possible that the plastic limit, which is the optimum water content of a saturated soil at which it behaves as a plastic material and thus can be molded to any shape, thereby the soil can be compacted or molded to the densest possible state at that water content. A simple method to predict the compaction curve is proposed based on the plastic limits of the soils. Of all the important engineering properties both volume change (compressibility and swelling) and hydraulic conductivity have good correlation with the shrinkage index. However, the compaction characteristics correlate well with the plastic limit. Herein, a hypothesis is proposed to possibly explain why shrinkage index has shown to be a better parameter to correlate with most of the engineering properties with the exception of the compaction characteristics. Recently it has been well brought out that shrinkage limit is primarily a function of how the varying grain sizes are distributed in a soil. Thus, shrinkage limit takes care of the gradation of the soil 
fractions in it. So, by considering the shrinkage index, which is the difference of the liquid limit water content on one end and shrinkage limit water content on the other end, the primary physical properties of the soils namely the plasticity and the grain size distribution are considered. And in that way compaction can be related to it.

\subsection{Objective}

The objective of this project is to investigate the feasibility of co-relation between plastic limit and optimum moisture content of cohesive soils.

\subsection{Scope}

Scope of this project work is limited to investigation on different C- $\phi$ soils.

\subsection{Necessity}

Compaction of soil is a very frequent activity in majority of Civil Engineering Projects. Determination of compaction characteristics is very necessary for effective planning. The laboratory determining of compaction characteristics is time consuming and requires a lot of efforts. Hence, there is a need for a method to predict the compaction characteristics through index properties which are determinable easily. This study is therefore necessary for development of a correlation for prediction of optimum moisture content in terms of plastic limit.

\section{LITERATURE REVIEW}

Prediction as a tool in engineering has been used in taking right judgments in many of the professional activities. This being the fact, the role and significance of prediction in geotechnical practices is important. All manmade structures are either made of soil or are resting on natural soil, involving large quantities of soil. Thus, it is often necessary for the Geotechnical Engineer to quickly characterize the soil and determine its Engineering properties, so as to assess the suitability of it for any specific purpose. Obtaining these properties requires undisturbed samples, which involves time and money, and also elaborates all the laboratory procedures. Thus, it is desirable to find simpler and quicker methods of testing, using the data of which the Engineering properties can be predicted satisfactorily for preliminary designing purposes. Most often this can be achieved from simple tests known as inferential tests, and the Engineering properties namely, compressibility, swell/collapse behavior, hydraulic conductivity, strength and compaction characteristics can be obtained from empirical/semiempirical correlations.

The index tests namely the Atterberg limits form the most important inferential soil test with wide universal acceptance. These tests are relatively simple to perform and have provided a basis for explaining most of the engineering properties of soils in geotechnical practice. Any good correlation in the prediction of engineering properties with the index properties will enhance the use of simple test for prediction purposes. It is often necessary to identify the basic mechanisms controlling the engineering properties from a micro-mechanistic point of view and correlate with the index properties, thereby facilitating prediction of engineering properties better.

Though attempts have been made in the past to predict the engineering properties of soils from the index properties, new method has been proposed to predict the plasticity index in terms of the flow index. [7] Sridharan et.al (1999) tried to determine the Plasticity Index from Flow Index. Considering the human errors involved in the thread method of determining the plastic limit, they proposed a method to predict consistent limits and also to save the time. The flow index is the slope of the water content versus log10 (number of blows) plot in the percussion cup method or the slope of the water content versus $\log 10$ (depth of penetration) plot of the cone penetration method of determining the liquid limit of soils is a measure of soil plasticity, so, the plasticity index of a soil that represents the soil plasticity can be correlated with the flow index.

The prediction of the plasticity index from the cone method was observed to be better than that from the percussion cup method.

In past, a lot of attempts have been made to predict compaction characteristics of soil. [1] Johnson and Sallberg (1962) plotted a chart for liquid limit verses plastic limit and indicated different zones for OMC. This chart is useful for prediction of OMC. [2] Pandian et.al (1997) gave a series of predicted compaction curves for Proctor compaction effort for different values of degree of saturation, ranging from wet and dry side of optimum. The range of $50 \%, \mathrm{Sr}, 85 \%$ on the dry side of optimum and $85 \%, \mathrm{Sr}, 95 \%$ on the wet side of optimum, the water content can be calculated using equations bellow. With the help of the predicted set of compaction curves, the dry unit weight can be determined, and hence the dry unit weight-water contents path.

Dry side of optimum:

$$
\mathrm{W} / \operatorname{Sqrt}\left(\mathrm{S}_{\mathrm{r}}\right)=9.46+0: 2575 \mathrm{~W}_{\mathrm{L}}
$$

Wet side of optimum:

$$
\mathrm{W} / \mathrm{S}_{\mathrm{r}}^{2}=10: 61+0: 3615 \mathrm{~W}_{\mathrm{L}}
$$

Where, $\mathrm{S}_{\mathrm{r}}$ is degree of saturation, $\mathrm{W}_{\mathrm{L}}$ is liquid limit and Srqt is abbreviation for square root.

But the above equation were proved to be unsatisfactory. [3] A.Sridharan and H.B Nagaraj (2005) did a study on 5 pairs of soils with nearly same liquid limit but different plasticity index among the pair and tried to predict optimum moisture content and maximum dry density from plastic limit of soil. They proposed the following formula:

$$
\begin{gathered}
\text { OMC }=0: 92 W_{\mathrm{P}} \\
\Upsilon_{\mathrm{dmax}}=0: 23\left(93: 3-\mathrm{W}_{\mathrm{P}}\right)
\end{gathered}
$$


Where, $W_{p}$ is plastic limit in percentage and $\Upsilon_{d \max }$ is maximum dry density in $\mathrm{KN} / \mathrm{m}^{3}$. Their study concludes that $\mathrm{OMC}$ is nearly equal to plastic limit.

Recently, [4] Shahid noor and Amardeep singh (2012) developed a prediction models for soil from a hydroelectric plant, to estimate compaction characteristics using genetic programing. They developed an equation which is valid only for a soil with particular characteristics. The equations are: $\mathrm{OMC}=(\mathrm{PI} / \mathrm{G})+3.4241823+(0.4624983 * \mathrm{PL})-\mathrm{G}$

$$
\begin{aligned}
\mathrm{MDD}= & ((-0.0890392) * \mathrm{LL})+19.046925+(\operatorname{Sqrt}(\mathrm{PL}) \\
& +33.974626) /(\mathrm{PL}-(-1.3710165))
\end{aligned}
$$

Where, LL is liquid limit, PL is plastic limit and $G$ is specific gravity.

\section{METHODOLOGY}

A set nine different types of fine grained soils were selected from different parts of Telengana and Andhra Pradesh. The samples were both natural soils and commercially available kaolinites like china clay etc. The natural soils were extracted from a depth of about $0.5 \mathrm{~m}$ below the natural ground surface. Then the soil was allowed to dry at room temperature thoroughly. Dried soil consisting of lumps was pulverized gently so as not to crush the individual particles. The soil then was sieved through $4.76 \mathrm{~mm}$ (IS. 480) sieve and was stored in the containers. Detailed tests were conducted to assess the index properties as well as the engineering properties of the soil.

All the soils were characterised for their physical properties namely, particle size distribution, consistency limits, optimum moisture content and maximum dry density using standard procedures.

The plastic limit of fine grained soils are the reflection of both strength and deformability. As such, most of methods of determination of plastic limit involve shaping wet clays of different consistencies into balls and threads, and subjecting them to different types of manipulation. The most commonly used method is the thread rolling method in which wet clay is rolled into threads and the limiting water content is determined when the threads begin to break when rolled to $1 / 8$ inch $(3 \mathrm{~mm})$ diameter.

Compaction characteristics were found by doing modified compaction test according to Indian standard specification IS: 2720 (Part VIII -1980). About four to five trails were done varying initial water content.

Then Regression analysis is done to develop correlation. The results of the soils were utilized to fit a best curve with the help of Regression Analysis. The probabilistic model is developed to predict Optimum Moisture Content as a function of Plastic Limit.

\section{RESULTS AND DISCUSSION}

The test results of consistency limits and compaction characteristics are given bellow in the Table- 1 and Table- 2 respectively.

Table-1: Soil type and Consistency limits

\begin{tabular}{|l|l|l|l|l|l|}
\hline $\begin{array}{l}\text { S.R } \\
\text { no }\end{array}$ & Description & $\begin{array}{l}\text { Soil } \\
\text { type }\end{array}$ & $\begin{array}{l}\text { Liquid } \\
\text { limit } \\
\%\end{array}$ & $\begin{array}{l}\text { Plastic } \\
\text { limit } \\
\%\end{array}$ & $\begin{array}{l}\text { Plasticity } \\
\text { Index \% }\end{array}$ \\
\hline 1 & B.C Soil 1 & CH & 50.0 & 31.4 & 18.5 \\
\hline 2 & B.C Soil 2 & CI & 58.1 & 29.9 & 28.2 \\
\hline 3 & Brown Clay & CI & 50.0 & 20.7 & 29.3 \\
\hline 4 & China Clay & CH & 72.0 & 27.9 & 44.08 \\
\hline 5 & $\begin{array}{l}\text { Marine } \\
\text { Clay }\end{array}$ & CH & 63.8 & 22.3 & 41.5 \\
\hline 6 & B.C Soil 3 & CH & 52 & 23.2 & 28.8 \\
\hline 7 & Slity Clay & CH & 56.0 & 22 & 34.0 \\
\hline 8 & B.C Soil 4 & CH & 48.8 & 21.6 & 27.2 \\
\hline 9 & Red soil & CL & 41.2 & 32.5 & 8.49 \\
\hline
\end{tabular}

A graph is plotted to correlate optimum moisture content and plastic limit.

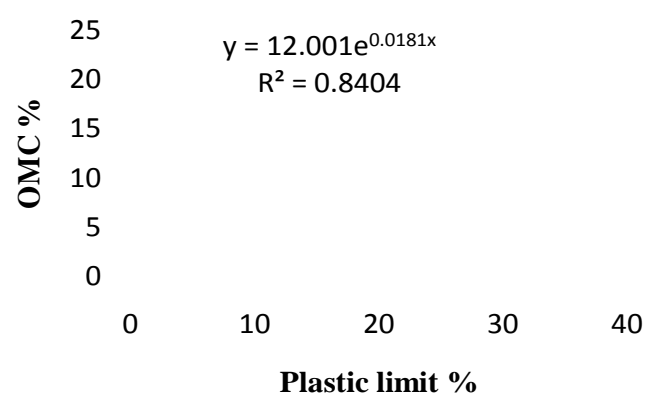

Graph-1: OMC vs. Plastic limit

The graph shows exponential relation between plastic limit and OMC.

The equation found by the relation is,

$$
\mathrm{OMC}=12.001 \mathrm{e}^{0.0181 \mathrm{PL}}
$$

Where, OMC is optimum moisture content in percentage and PL is plastic limit in percentage.

A comparison between $\mathrm{OMC}$ found by proctor test and OMC found by the equation proposed is given in the Table below:

Table-2: Compaction characteristics of soil found with proctor test and proposed equation

\begin{tabular}{|l|l|l|}
\hline $\begin{array}{l}\text { OMC \% } \\
\text { By proctor test }\end{array}$ & $\begin{array}{l}\text { OMC\% } \\
\text { By proposed } \\
\text { equation }\end{array}$ & $\begin{array}{l}\text { MDD } \\
\text { gm/cc }\end{array}$ \\
\hline 20.95 & 21.18 & 1.64 \\
\hline 21.4 & 20.61 & 1.62 \\
\hline
\end{tabular}




\begin{tabular}{|l|l|l|}
\hline 18.52 & 17.45 & 1.64 \\
\hline 19.72 & 19.88 & 1.29 \\
\hline 17.86 & 17.9 & 1.36 \\
\hline 17.8 & 18.26 & 1.91 \\
\hline 16.7 & 17.87 & 1.81 \\
\hline 18.11 & 17.74 & 1.6 \\
\hline 21.5 & 21.61 & 1.678 \\
\hline
\end{tabular}

\section{CONCLUSION}

Based on the experiment results, it is found that the correlation between optimum moisture content and plastic limit is feasible in respect of fine grained soils. The correlation based on the investigation in this study is given bellow:

$$
\mathrm{OMC}=12.001 \mathrm{e}^{0.0181 \mathrm{PL}}
$$

With $\mathrm{R}^{2}=0.8404$

The $\mathrm{R}^{2}$ is reasonably good. The table 2 shows that the predicted OMC is nearly same as the one found by proctor test.

The study highlights the need for careful determination of the plastic limit of soil. Although it is generally felt that the plastic limit test is arbitrary. .

\section{REFERENCES}

[1]. Johnson A. W. and Sallberg J. R. (1962) Factors influencing compaction results. Highway Research Board Bulletin, No. 319, 125

[2]. Pandian N. S., Nagaraj T. S. and Manoj M. (1997) Reexamination of compaction characteristics of fine-grained soils. Geotechnique, 47, No. 2, 363-366

[3]. A. SRIDHARAN* and H. B. NAGARAJ, "Plastic limit and compaction characteristics of fine grained soils Ground Improvement" (2005) 9, No. 1, 17-22

[4]. AMARDEEP SINGH, SHAHID NOOR, "Soil Compression Index Prediction Model for Fine Grained Soils"

[5]. BSI (1990) British standard methods of tests for engineering purpose: Compaction- related tests, BS 1377: Part 4. London: British standards institution.

[6]. Terzaghi, K. and Peck, R. B. (1967), "Soil Mechanics in Engineering Practice.” John Wiley, London. 1 Issue 4 Dec 2012

[7]. A. Sridharan, H. Nagaraj and K. Prakash, "Determination of the Plasticity Index from Flow Index," Geotechnical Testing Journal, GTJODJ, Vol. 22, No. 2, June 1999, pp. 169-175.

[8]. Skempton, A. W. (1944), "Notes on the Compressibility of Clays.” Q. J. Geol. Soc. London, 100(1-4), 119-135.

[9]. Terzaghi, K. and Peck, R. B. (1967), "Soil Mechanics in Engineering Practice.” John Wiley, London. 1 Issue 4 Dec 2012.

[10]. Region Berawala, K. S. Solanki, "Empirical Correlations of Expansive Soils Parameters for the Surat" Indian Geotechnical Conference - 2010, GEOtrendz
December 16-18, 2010 IGS Mumbai Chapter \& IIT Bombay.

[11]. Orhan Erol, Yusuf Erzin "Correlations for Quick Prediction of Swell Pressures" (2003), Electronic journal of Geotechnical Engineering

\section{BIOGRAPHIES}

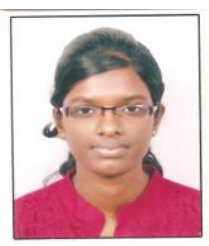

K.Hannah Jyothirmayi, M.Tech student, VNR Vignana Jyothi Institute of Engineering and Technology, Hyderabad, Telengan

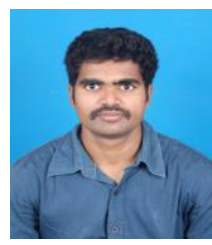

T.Gnananda Rao, Asst. Professor, VNR Vignana Jyothi Institute of Engineering and Technology, Hyderabad, Telengana

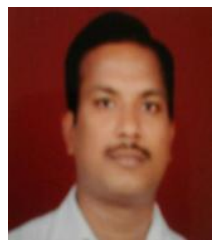

K.Suresh, Asst. Professor, VNR Vignana Jyothi Institute of Engineering and Technology, Hyderabad, Telengana 